\title{
Acid functionalized carbons as catalyst for glycerol etherification with benzyl alcohol
}

\author{
María E. Chiosso ${ }^{1} \cdot$ Ileana D. Lick $^{1} \cdot$ Mónica L. Casella ${ }^{1} \cdot$ Andrea B. Merlo $^{1}$
}

Received: 14 December 2018 / Revised: 7 August 2019 / Accepted: 12 September 2019

(c) Associação Brasileira de Engenharia Química 2020

\begin{abstract}
In this paper, the catalytic behaviour of two different carbonaceous systems, commercial carbon $(\mathrm{Cc})$ and synthetic carbon (Cs) functionalized with concentrated sulfuric acid $\left(-\mathrm{SO}_{3} \mathrm{H}\right)$ and with reduced aryl diazonium salt $\left(-\mathrm{PhSO}_{3} \mathrm{H}\right)$, was studied in the etherification of glycerol (Gly) with benzyl alcohol (BA). The catalytic activity and selectivity were studied varying the catalyst percentage $(5,10$ and $15 \mathrm{wt} \%)$ and the initial reactant mass ratio. Taking into account the results obtained, the experimental conditions selected to continue with the catalytic studies were: temperature $393 \mathrm{~K}$, Gly:BA molar ratio 3:1 and a catalyst loading of $10 \mathrm{wt} \%$. Mono- and diethers were the main products. For the Cc-based catalysts, higher conversion $(66 \%)$ and selectivity $(90 \%)$ were obtained with the most acidic system, $\mathrm{Cc}-\mathrm{PhSO}_{3} \mathrm{H}$. Changing the carbon functionalization method (- $\mathrm{PhSO}_{3} \mathrm{H}$ for $-\mathrm{SO}_{3} \mathrm{H}$ groups) produced a considerable increase in glycerol conversion (from 23 to $66 \%$ ) and in selectivity to ME + DE (from 62 to 90\%). On the other hand, for both Cs-based systems a great increase in performance was obtained, about $95 \%$ conversion after $360 \mathrm{~min}$ of reaction. Monoether was the major product of the reaction with a selectivity of $79 \%$ for $\mathrm{Cs}-\mathrm{SO}_{3} \mathrm{H}$ and $87 \%$ for $\mathrm{Cs}-\mathrm{PhSO}_{3} \mathrm{H}$, which was maintained with reuse.
\end{abstract}

\section{Graphic abstract}

Etherification of glycerol (Gly) with benzyl alcohol (BA) with two carbonaceous systems synthesized in the laboratory and functionalized with $-\mathrm{SO}_{3} \mathrm{H}$ and $-\mathrm{PhSO}_{3} \mathrm{H}$.

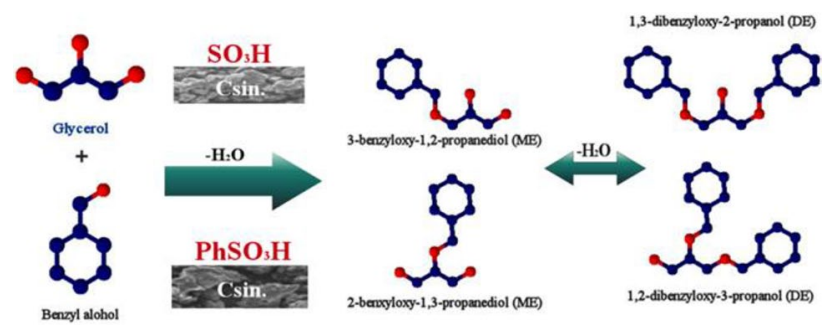

Keywords Glycerol · Etherification · Acid catalysts · Sulfonated carbon · Benzyl alcohol

Andrea B. Merlo

andreamerlo@quimica.unlp.edu.ar

1 Centro de Investigación y Desarrollo en Ciencias Aplicadas "Dr. Jorge J. Ronco" (CINDECA), CCT La Plata-CONICET, Departamento de Química, Facultad de Ciencias Exactas, Universidad Nacional de La Plata, Calle $47 \mathrm{~N}^{\circ} 257$, 1900 La Plata, Argentina

\section{Introduction}

Current problems of the energetic crisis due to the depletion of fossil fuels, high oil prices and the effects on the environment caused by the emission of hazardous and chemicals products into the atmosphere have forced us to look for alternatives to replace these fuels. Biodiesel is a renewable and biodegradable alternative to fossil fuels, and because of this, it is expected that its use will continue growing in the future (Anitha et al. 2016; Bozkurt 2015). 
Biodiesel produced from vegetable oil, animal tallow, oils and fats is a promising biofuel to be mixed with diesel or used directly. However, one of the main obstacles to the commercialization of biodiesel is the by-product glycerol, since each ton of biodiesel originates $100 \mathrm{~kg}$ of glycerine that saturates the market, causing a dramatic reduction in prices and, consequently, negatively effects biodiesel economy (Anitha et al. 2016; Janaun and Ellis 2010).

The direct combustion of glycerol is not feasible in engines because of its high viscosity, low heating value, high auto-ignition temperature and corrosive salt content (for crude glycerol). Moreover, its incomplete combustion can be carcinogenic due to the production of acroleine (Bohon et al. 2011).

Therefore, in recent years several processes to produce value-added chemicals from glycerol have been reported, such as hydrogenolysis, etherification, esterification, dehydratation, oxidation and others (Len and Luque 2014; Faroppa et al. 2016; Jaworski et al. 2015; Pagliaro et al. 2007; Alonso et al. 2012).

A wide range of chemical products can be derived from glycerol, making sure that in the future glycerol will become an important renewable raw material for biorefineries. Although researchers have developed various methods for using glycerol as fuel additives, these methods are still at the laboratory scale and their actual cost for production is unknown.

The etherification process of glycerol is an interesting application that could be industrially important to obtain compounds of lower viscosity and higher volatility than glycerol, which could be used as oxygenated additives for liquid fuels, intermediates for pharmaceutical products, agrochemicals, nonionic surfactants, etc. (Gonçalves et al. 2013, 2016). As a function of the alcohol used, selective glycerol etherification may also lead to obtaining a wide range of products having biological applications, such as anti-inflammatory, antibacterial, antifungal and antitumor products, among others (Gu et al. 2008).

Glycerol etherification with benzyl alcohol (BA) is an acid-catalyzed reaction, resulting in a mixture of three products. Besides, a by-product of BA self-condensation (dibenzyl ether, BE), can also be formed (Scheme 1) (Jaworski et al. 2015).

This reaction can be carried out using homogeneous or heterogeneous acid catalysts.

There are several reports of acid catalysts used in the etherification of glycerol with benzyl alcohol. Gu et al. obtained $73 \%$ and $96 \%$ yield with the catalyst $\mathrm{SiO}_{2}-\mathrm{SO}_{3} \mathrm{H}$ (under conditions Gly:BA =1:1 and 4.2:1, respectively) and $100 \%$ of ME. In that publication the results with a $\mathrm{C}-\mathrm{SO}_{3} \mathrm{H}$ system were also shown, but only $12 \%$ yield was reported (Gu et al. 2008). Da Silva et al. (2009) obtained the best performance with the systems Amberlyst-35 (37\% ME, 20\% $\mathrm{DE}, 3 \% \mathrm{TE}$ and $30 \% \mathrm{BE}$ ) and Zeolite $\beta(55 \% \mathrm{ME}, 3 \% \mathrm{DE}$, $1 \% \mathrm{TE}$ and $38 \% \mathrm{BE}$ ), for a $100 \%$ conversion after $120 \mathrm{~min}$ of reaction. Conversion of $70 \%$ of BA was reported (for 360 min of reaction) using $2.5 \%$ of sulfated zirconia ( $2 \mathrm{~S} /$ $\mathrm{ZrO}_{2}$ ) as catalyst and the distribution of products was the following: 40\% S ME, 30\% S DE and 30\% S BE (Jaworski et al. 2015). On the other hand, Zeolite Z15c as catalyst for the etherification of Gly with BA (ratio 1:1 and $393 \mathrm{~K}$ ) produced ME (60\%) and DE (38\%), with little BE formation (2\%), for $80 \%$ of BA conversion after $8 \mathrm{~h}$ reaction (Gonzalez-Arellano et al. 2015).
Scheme 1 Reaction network for glycerol etherification with benzyl alcohol

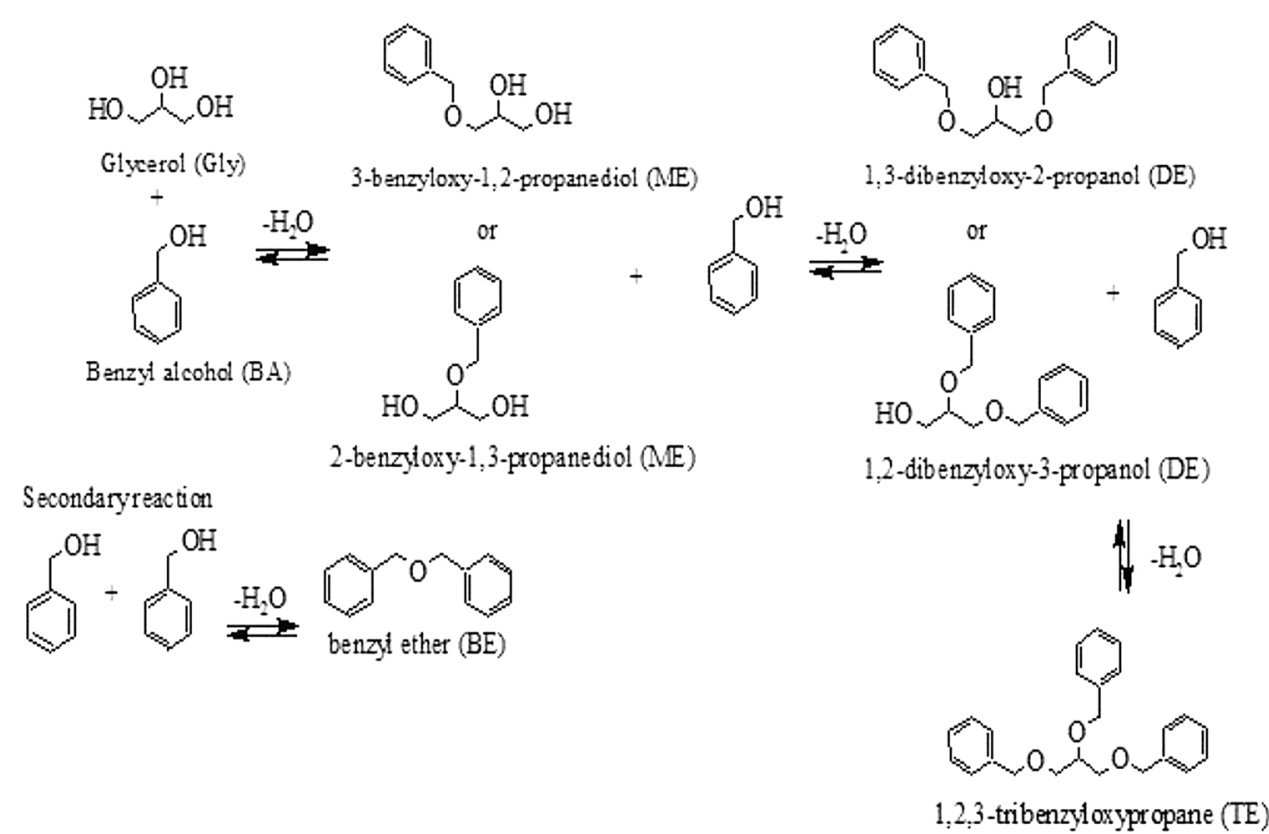


Carbonaceous materials are a good alternative. Scientific production with these materials during the last 20 years has been increasing considerably (González-García 2018).

The surface chemistry of carbonaceous materials determines their physicochemical and acid-base properties, and hydrophobic characteristics. This is defined by the presence of different atoms of carbon and the formation of functional groups. Oxygenated groups are generated in large quantities as a result of the chemical reaction between the active centres of the carbon with the oxygen coming from the precursor material or any other oxidizing agent present in the reaction medium (Martínez Fierro 2012). Of the functional groups that can be found on the surface of activated carbon, carboxylic acids, lactones, anhydrides or phenols confer an acidic character. Nevertheless the presence of groups such as quinones, pyrones and chromenes give it a basic character. In general, the surface of active carbon is hydrophobic; however, the presence of acidic oxygenated groups gives the surface a certain hydrophilic character (Boehm 1994).

Among the supports and catalysts used in the etherification of glycerol is also carbon. The most direct way to obtain a carbonaceous material is by pyrolysis of carbohydrates, such as glucose or sucrose, at relatively mild temperature (573-673 K) in an inert atmosphere. Biomass resources can also be used (Gonçalves et al. 2013, 2014, 2016; RodríguezReinoso 1998; Han et al. 2003). Among these materials, those functionalized with sulfonic acid groups have been investigated as potential catalysts (Toda et al. 2005; Janaun and Ellis 2010; Sánchez et al. 2011; Liu et al. 2008, 2013). In this work, carbon acid catalysts were prepared from dextrose and functionalized with sulfonic acid groups to be used in the etherification of glycerol with benzyl alcohol. The effect of several operational variables (percentage of catalyst, Gly:BA molar ratio) as well as the reusability of the catalysts, have been evaluated.

There are many reports of glycerol etherification using acidic carbons, but there are very few papers where benzyl alcohol is used and the results are not good (Gu et al. 2008). Because of this, our research addresses the challenge of finding an acid carbonaceous system that will be an efficient catalyst in this reaction. Therefore, the main objective of this work was to obtain (with good performance and low cost) a functionalized carbonaceous system, comparable to a commercial carbon in efficiency in the etherification reaction.

\section{Materials and methods}

Reagent for $C$ synthesis: dextrosa (anhydrous, Anedra Poranalysis), sodium silicate solution (J.T. Baker $27 \% \mathrm{SiO}_{2}$ ), hydrochloric acid (Anedra 37\% p/p), sodium hydroxide (Merck Pro-analysis).
Reagent for functionalization of carbon: sulfuric acid (J.T. Baket 98\%), 4-aminobenzenesulfonic acid (Biopack Pro-analysis), hypophosphorous acid (Biopack 50\% Pro-analysis).

Etherification Reagent: glycerol (Biopack 99.5\%), benzyl alcohol (Anedra analytic reagent), 1-butanol (Baker analysed), ethyl alcohol (Cicarelli 99.5\% absolute).

\section{Catalyst preparation}

NORIT C (GAC 1240 PLUS), which was ground to a particle size of 60 to 100 mesh, was used as commercial carbon catalyst $(\mathrm{Cc})$. The synthesized carbon catalyst $(\mathrm{Cs})$ was obtained from dextrose, following similar procedure that published by Han et al. (2003). This method comprises a template-assisted carbonization process for the synthesis of the carbonaceous material. The anhydrous dextrose was used as carbon precursor ( $15 \mathrm{~g}$ ) and the commercial sodium silicate solution $(20 \mathrm{~mL})$ as source of $\mathrm{SiO}_{2}$ to develop the template. The key step in the procedure is the co-polymerization of dextrose with the sodium silicate. After complete dissolution, hydrochloric acid was added, producing a brown solution. The reaction mixture was kept for $24 \mathrm{~h}$ at $343 \mathrm{~K}$ to achieve evaporation of residual water and polymerization. Carbonization of the material was performed under a nitrogen atmosphere in two steps: the first one at $473 \mathrm{~K}$ and the second one at $723 \mathrm{~K}$, both for a period of $5 \mathrm{~h}$. The resulting material was stirred in $3 \mathrm{M} \mathrm{NaOH}$ for $5 \mathrm{~h}$ to remove the silica "template". Then, the carbon was recovered by filtration and dried in an oven at $378 \mathrm{~K}$.

\section{Carbon functionalization}

Two methods for the sulfonation of the carbon materials were used. In the first, the solid was contacted with concentrated $\mathrm{H}_{2} \mathrm{SO}_{4}$, using a ratio of $15 \mathrm{~mL}$ of acid per gram of solid, at $423 \mathrm{~K}$ and under a $\mathrm{N}_{2}$ current. Then, the sulfonated material was washed with distilled water, filtered and dried for $2 \mathrm{~h}$ at $378 \mathrm{~K}\left(\mathrm{C}-\mathrm{SO}_{3} \mathrm{H}\right)$. The second method consists of the reaction between 4-benzene-diazonium sulfonate and the carbon material, using hypophosphorous acid $\left(\mathrm{H}_{3} \mathrm{PO}_{2}\right)$ as the reducing agent (Liu et al. 2010). The synthesis of 4-benzene-diazonium sulfonate was carried out by diazotization of 4-aminobenzenesulfonic acid. The $\mathrm{C}-\mathrm{PhSO}_{3} \mathrm{H}$ obtained was filtered and washed with distilled water ( $\mathrm{Ph}$ : phenyl group).

\section{Catalyst characterization}

The total acid site density was determined by back titration. In a typical test, $50 \mathrm{~mL} \mathrm{NaOH}$ were added to $0.1 \mathrm{~g}$ of dried carbon and kept under stirring for $30 \mathrm{~min}$ at room temperature. Subsequently, the excess $\mathrm{NaOH}$ was titrated with $\mathrm{HCl}$ 
solution until the endpoint. This analysis was performed on carbon samples both with and without functionalization.

The surface properties and porosity of the carbonaceous materials were analyzed by isothermal adsorption/desorption of $\mathrm{N}_{2}$ at $77 \mathrm{~K}$ in a Micromeritics Accusorb 2100 E equipment, Scanning Electron Microscopy (SEM) was performed using a Philips SEM 505. The carbon samples were placed inside the microscope chamber and evacuated to high vacuum. Energy dispersive X-ray spectroscopic (EDX) analysis was performed to detect the presence of sulphur in the functionalized systems.

Fourier transform infrared spectroscopy (FTIR) was recorded in a Jasco 4200 spectrometer in transmittance mode, on samples embedded in $\mathrm{KBr}$ pellets. The spectra were obtained between 400 and $4000 \mathrm{~cm}^{-1}$.

Thermogravimetric analysis (TGA) was performed using a Shimadzu TGA-50 thermal analyzer. Sample mass was recorded during heating at a constant temperature rate of $10 \mathrm{~K} \mathrm{~min}^{-1}$, from 298 to $973 \mathrm{~K}$, under a $\mathrm{N}_{2}$ flow of $100 \mathrm{~mL} \mathrm{~min}^{-1}$.

\section{Catalytic tests}

Etherification of Gly with BA was conducted under a $\mathrm{N}_{2}$ atmosphere, at $393 \mathrm{~K}$ and atmospheric pressure, with constant stirring in a glass reactor. The reaction time was $360 \mathrm{~min}$. $\mathrm{Cc}-\mathrm{SO}_{3} \mathrm{H}$ was selected to optimize the Gly:BA molar ratio $(1: 1,3: 1$ or $5: 1)$ and the mass of catalyst in relation to the mass of glycerol employed $(5,10$ or $15 \mathrm{wt} \%)$. The sample was taken at the end of the reaction, filtered and analysed by gas chromatography. The analyses were carried out using a Varian $C P-3800$ gas chromatograph equipped with a capillary column $C P$ WAX $52 C B$ (30 m; $0.53 \mathrm{~mm}$ i.d.) and a FID detector.

The response factors of Gly and BA were determinated using butyl alcohol as internal standard for the calibration curve. Commercial ( \pm ) 3-benzyloxy-1,2-propanediol and 1,3-dibenzyloxy-2-propanol were employed to obtain the corresponding response factors. EB was calibrated as well.

The reaction products were identified using a $G C / M S H P$ 5890 gas chromatograph with a HP5-MS $(30 \mathrm{~m}, 0.25 \mathrm{~mm}$ i.d.) column.

For reuse tests, the catalysts, in a typical experiment after finishing the etherification reaction, were filtered, washed with water, dried in an oven at $378 \mathrm{~K}$ for $24 \mathrm{~h}$, and reused under these conditions: $393 \mathrm{~K}, 10 \%$ of catalyst and Gly:BA molar ratio 3:1.

\section{Results and discussion}

\section{Catalyst characterization}

Table 1 shows the results obtained for surface analysis and acid site density of the materials used. The amount of acid sites is very important in the glycerol etherification reaction. In particular, sulfonic groups play a crucial role as active sites for such reaction. In this sense, Table 1 shows that the acidic sites of both carbons increase significantly after functionalization, reaching the highest values for synthesized carbon $\left(\mathrm{Cs}-\mathrm{SO}_{3} \mathrm{H}\right.$ and $\left.\mathrm{Cs}-\mathrm{PhSO}_{3} \mathrm{H}\right)$. The high density of sulfonic groups can be explained by the relatively soft carbonization temperature used $(723 \mathrm{~K})$, which produces an amorphous but more active surface towards the sulfonation (Sánchez et al. 2011). It can also be seen that, when comparing $\mathrm{Cs}$ and $\mathrm{Cc}$ carbons, a higher acid density is obtained with the first one ( 0.4 vs. $\left.0.05 \mathrm{mmol} \mathrm{g}^{-1}\right)$, a fact that can be attributed to the additional contribution of $-\mathrm{COOH}$ and $-\mathrm{OH}$ groups generated as products of the incomplete carbonization of the starting sugar. Strong sulfonation can also oxidize aliphatic $\mathrm{CH}_{3} / \mathrm{CH}_{2}$ groups to carboxylic acid groups, which could contribute to explain the increase in acid site density (Mo et al. 2008).

The $\mathrm{N}_{2}$ adsorption/desorption results shown in Table 1 are in agreement with those published by other authors. In the case of $\mathrm{Cs}$, the use of $\mathrm{Na}_{2} \mathrm{SiO}_{3}$ plays a very important role as a "director" of the pore structure. This Table also shows that, after functionalization treatment, the surface area and $\mathrm{Vp}$ decreased for both carbon systems ( $\mathrm{Cc}$ and $\mathrm{Cs}$ ). These results show that sulfonic groups were introduced successfully on the surface (Sánchez et al. 2011).

Figure 1 shows the SEM micrographs and the EDX spectra obtained for $\mathrm{Cs}-\mathrm{SO}_{3} \mathrm{H}$ and $\mathrm{Cs}-\mathrm{PhSO}_{3} \mathrm{H}$ samples. For both functionalized $\mathrm{Cs}$ systems, the micrographs depict rather small carbon aggregates with flat surfaces, according to the low surface area values measured. The EDX measurements confirm the presence of sulfur on both catalysts. For the $\mathrm{Cc}-\mathrm{SO}_{3} \mathrm{H}$ and $\mathrm{Cc}-\mathrm{PhSO}_{3} \mathrm{H}$ systems, although not shown, similar diagrams were obtained (Goncalves et al. 2015; Tao et al. 2015).

FTIR spectra were recorded in order to confirm that the carbonization and sulfonization processes were successful

Table 1 Surface area, pore volume and acid site density of carbons and sulfonated materials studied

\begin{tabular}{llcl}
\hline Catalyst & $\begin{array}{l}\text { Acid density } \\
\left(\mathrm{mmol} \mathrm{H} \mathrm{g}^{+}\right)\end{array}$ & $\mathrm{S}_{\mathrm{BET}}^{\mathrm{a}}\left(\mathrm{m}^{2} \mathrm{~g}^{-1}\right)$ & $\mathrm{V}_{\mathrm{p}}{ }^{\mathrm{b}}\left(\mathrm{cm}^{3} \mathrm{~g}^{-1}\right)$ \\
\hline $\mathrm{Cc}$ & 0.05 & 1011 & 0.533 \\
$\mathrm{Cc}-\mathrm{SO}_{3} \mathrm{H}$ & 0.4 & 975 & 0.513 \\
$\mathrm{Cc}-\mathrm{PhSO}_{3} \mathrm{H}$ & 0.6 & 793 & 0.408 \\
$\mathrm{Cs}$ & 0.4 & 523 & 0.315 \\
$\mathrm{Cs}-\mathrm{SO}_{3} \mathrm{H}$ & 3.7 & 34 & 0.028 \\
$\mathrm{Cs}-\mathrm{PhSO}_{3} \mathrm{H}$ & 2.2 & 10 & 0.011
\end{tabular}

$C c$ commercial carbon NORIT (GAC 1240 PLUS), Cs carbon synthesized from dextrose

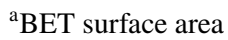

${ }^{\mathrm{b}}$ Pore volume 
Fig. 1 SEM micrographs and EDX spectra for: $\mathrm{Cs}-\mathrm{SO}_{3} \mathrm{H}$ and Cs- $\mathrm{PhSO}_{3} \mathrm{H}$
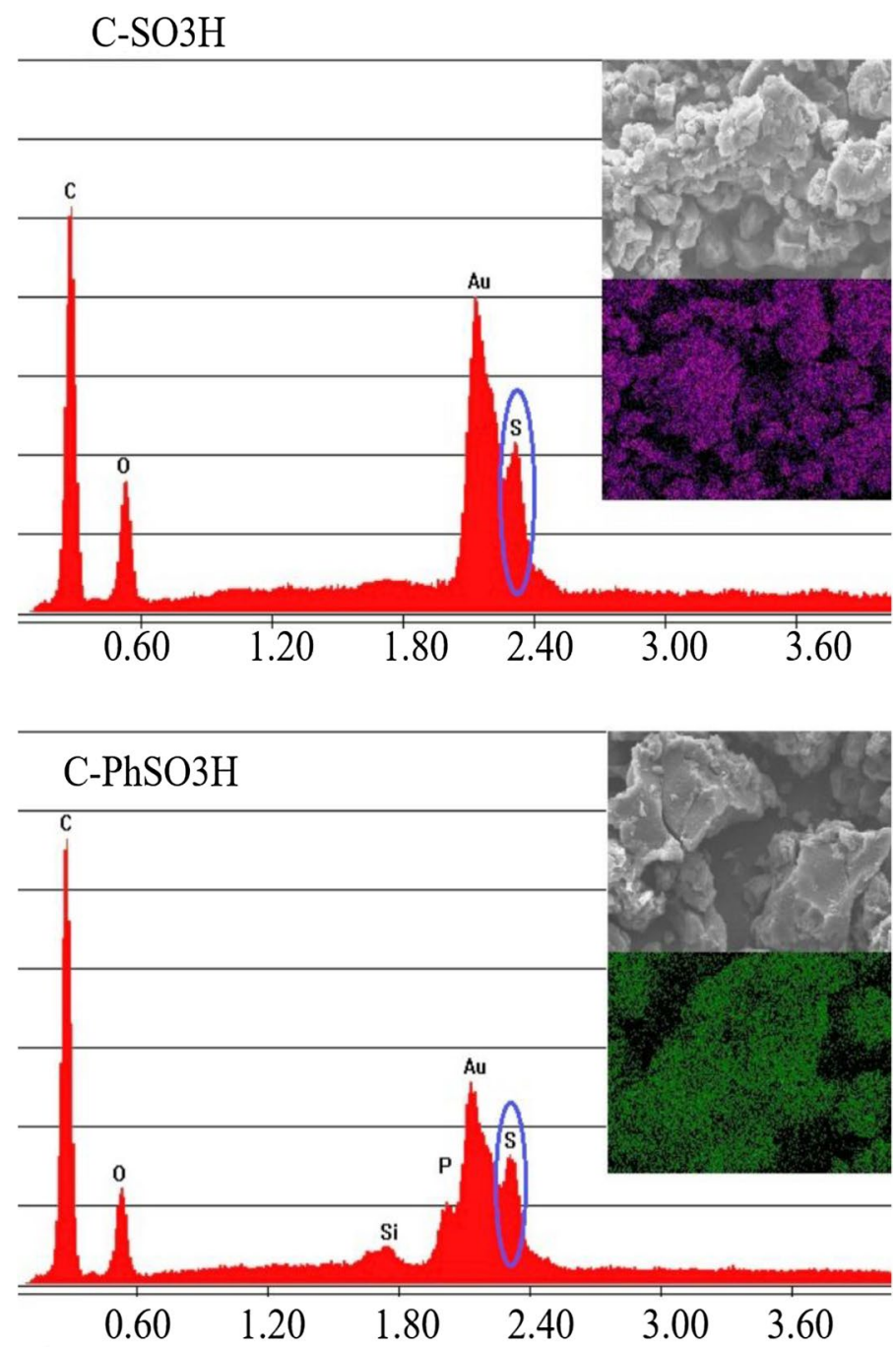

and to corroborate the presence of the characteristic bands that allow the identification of sulfonic, carboxylic and polycyclic aromatic carbons. Figure 2 shows the FTIR spectra for $\mathrm{Cs}, \mathrm{Cs}-\mathrm{SO}_{3} \mathrm{H}$ and $\mathrm{Cs}-\mathrm{PhSO}_{3} \mathrm{H}$ catalysts. All of them show a band around $1590 \mathrm{~cm}^{-1}$, which can be attributed to the stretching of the $\mathrm{C}=\mathrm{C}$ bonds formed as a consequence of the carbonization process (Zong et al. 2007; Toufiq Reza et al. 2016). Besides, a broad band located at $3440 \mathrm{~cm}^{-1}$ is found, which is associated with the $-\mathrm{OH}$ stretching mode. This band, which is more intense in the spectra of samples containing $-\mathrm{SO}_{3} \mathrm{H}$ groups, could originate from carboxylic and sulfonic groups. All the studied samples also present a band located at ca. $710 \mathrm{~cm}^{-1}$, associated with the stretching mode of the $\mathrm{C}=\mathrm{O}$ bond of the carboxylic group.

It should be noted that the band at about $3350 \mathrm{~cm}^{-1}$, assigned to the $\mathrm{N}-\mathrm{H}$ stretching absorption, does not appear in the $\mathrm{Cs}-\mathrm{PhSO}_{3} \mathrm{H}$ spectrum. The absence of this band is indicative of a successful diazotation step during the preparation of the functionalized carbon catalysts. On the other hand, a strong band at $1175 \mathrm{~cm}^{-1}$, that is assigned to the

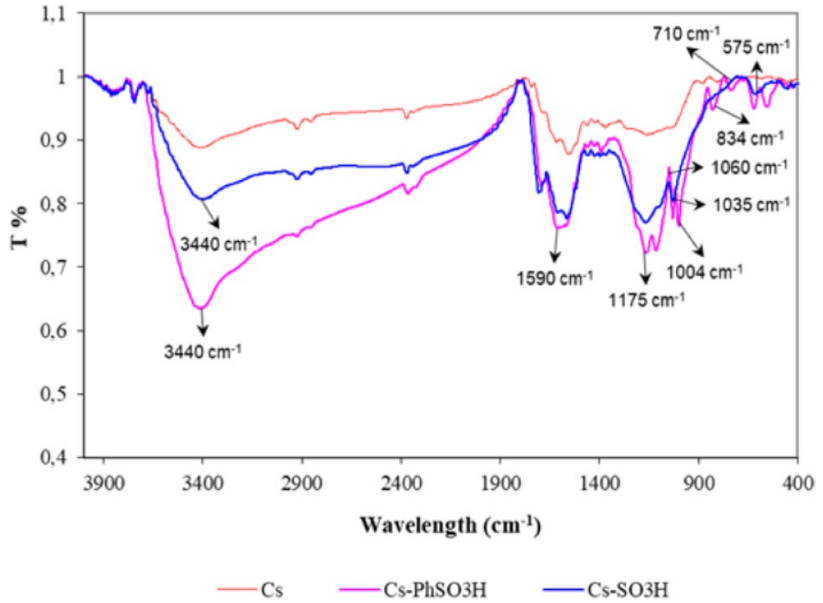

Fig. 2 FTIR spectra of: $\mathrm{Cs}, \mathrm{Cs}-\mathrm{SO}_{3} \mathrm{H}$ and $\mathrm{Cs}-\mathrm{PhSO}_{3} \mathrm{H}$ 
antisymmetric stretching mode of the $\mathrm{S}=\mathrm{O}$ group of $\mathrm{SO}_{2}$, can be observed in the $\mathrm{Cs}-\mathrm{SO}_{3} \mathrm{H}$ and $\mathrm{Cs}-\mathrm{PhSO}_{3} \mathrm{H}$ spectra. This band may be accompanied by a symmetrical stretching band at $1060 \mathrm{~cm}^{-1}$. The spectra also show absorption bands located at $1035 \mathrm{~cm}^{-1}$ and $1004 \mathrm{~cm}^{-1}$; these bands are associated with stretching modes of the $-\mathrm{SO}_{3}$ group. In the spectrum of the Cs- $\mathrm{PhSO}_{3} \mathrm{H}$ sample, a band at $834 \mathrm{~cm}^{-1}$, which is attributed to $\mathrm{S}-\mathrm{O}$ bonds, can be observed. In addition, a band at $575 \mathrm{~cm}^{-1}$ appears, assigned to the $\mathrm{C}-\mathrm{S}$ stretching mode. These bands confirm that the $-\mathrm{HSO}_{3}$ groups were successfully introduced onto the carbonaceous materials (Gonçalves et al. 2016; Figueiredo et al. 1999; Nersasian and Johson 1965).

Figure 3 shows a thermogravimetric analysis of Cs, Cs- $\mathrm{SO}_{3} \mathrm{H}$ and $\mathrm{Cs}-\mathrm{PhSO}_{3} \mathrm{H}$ catalysts. In this figure, the mass loss (wt \%) as a function of temperature (TGA curve) and the first derivative of the TGA curve (DrTGA curve) for each sample is shown. The DrTGA curves indicate at which temperature a mass loss process begins and ends.

The three catalysts present a first mass loss process, representing less than $15 \%$, which starts at low temperature $(<323 \mathrm{~K})$ and ends at approximately $403 \mathrm{~K}$. This process can be attributed to the loss of water. The base carbon, Cs (profile a), also exhibits a continuous mass loss between 474 and $1023 \mathrm{~K}$, attributed to the loss of functional groups in the form of gaseous molecules such as $\mathrm{CO}, \mathrm{CO}_{2}$. These compounds could be generated from the decomposition of several types of oxygen functional groups such as: carboxylic groups, anhydrides, phenols, carbonyl, quinones, lactones, polycyclic aromatic compounds, etc. (Figueiredo et al. 1999;

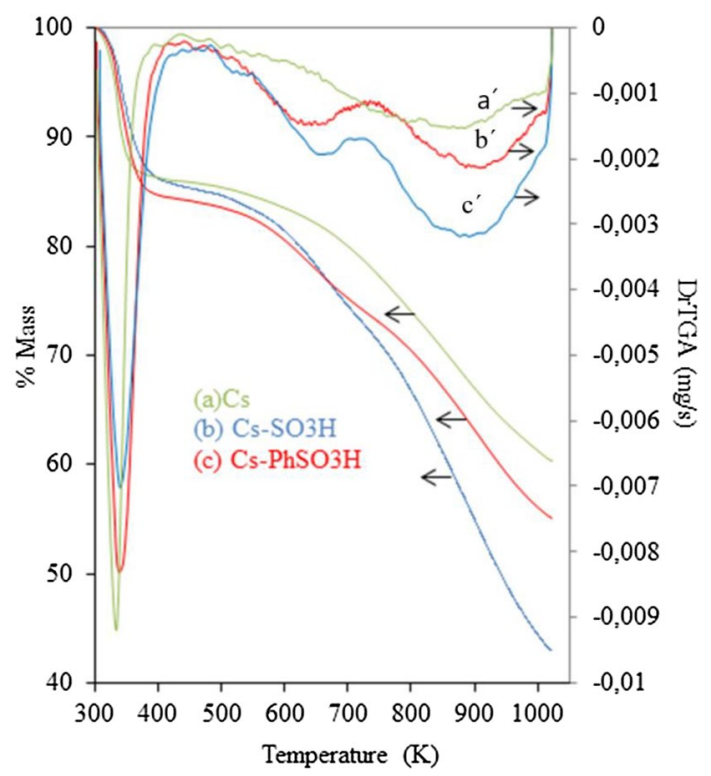

Fig. 3 TGA and DrTGA curves associated to mass loss of Cs (a), Cs$\mathrm{SO}_{3} \mathrm{H}(b)$ and $\mathrm{Cs}-\mathrm{PhSO}_{3} \mathrm{H}(c)$
Figueiredo and Pereira 2010). The total mass loss associated with these processes is approximately $40 \%$.

The $\mathrm{Cs}-\mathrm{SO}_{3} \mathrm{H}$ catalyst (profile b) shows three mass loss processes in addition to the water loss: one in the 473-533 K range, another from 533 to $700 \mathrm{~K}$ and the last one from 700 to $1023 \mathrm{~K}$. The total mass loss for these processes is $56 \%$. When comparing Cs and Cs- $\mathrm{SO}_{3} \mathrm{H}$ catalysts, it is worth noting the higher mass loss observed at temperatures lower than $673 \mathrm{~K}$ for the latter. This result could be associated with the loss of functional groups that are not present in the Cs. It has been reported that part of the sulfonic groups decompose in this temperature range (Gonçalves et al. 2014; Zhao et al. 2010a).

The Cs- $\mathrm{PhSO}_{3} \mathrm{H}$ catalyst (profile c) shows two mass loss processes, in addition to the water loss: the first one from 546 to $716 \mathrm{~K}$ and the other one from 716 to $1023 \mathrm{~K}$. The total mass loss associated with these processes is $44 \%$. The higher thermal stability of this catalyst with respect to the $\mathrm{Cs}-\mathrm{SO}_{3} \mathrm{H}$ catalyst is remarkable, a fact that could be associated with the preparation procedure. Nevertheless, it can be stated that all the catalysts are thermally stable in the temperature range in which they are used in the reaction.

\section{Catalytic results}

The catalysts ( $\mathrm{Cc}$ and $\mathrm{Cs}$ ) were studied in glycerol etherification using benzyl alcohol, at $393 \mathrm{~K}$ reaction temperature. The results obtained (conversions below 3\%) demonstrated that the base carbons do not have sufficient acidity and therefore are inactive for this reaction. This behavior can be explained by taking into account the fact that the etherification reactions require the presence of an acidic active site to take place.

\section{Influence of the Gly:BA molar ratio and of the catalyst percentage}

The effect of the initial concentration of the reactants was evaluated at $393 \mathrm{~K}$ using three Gly:BA molar ratios (1:1, 3:1 and 5:1) and $\mathrm{Cc}-\mathrm{SO}_{3} \mathrm{H}$ as catalyst. As can be seen in Table 2, the conversion of BA does not significantly change between the 1:1 and 3:1 molar ratios; however, a marked effect on the product distribution is observed. The selectivity for the desired products (ME and DE) was $62 \%$ when working under conditions of excess glycerol (3:1), while for the 1:1 molar ratio, the main product obtained was the undesired BE. Therefore, by increasing the Gly:BA initial mass ratio, the BE selectivity decreased (Jaworski et al. 2015). In Table 2, it can also be seen that, if the Gly concentration continues to increase (5:1 molar ratio), the selectivity to $\mathrm{ME}+\mathrm{DE}$ is even more favored. However the conversion obtained reaches only an $8 \%$ value after 360 min of reaction. 
Table 2 Etherification of Gly with BA at $393 \mathrm{~K}$, using $10 \mathrm{wt} \% \mathrm{Cc}-$ $\mathrm{SO}_{3} \mathrm{H}$ as catalyst

\begin{tabular}{lccccc}
\hline Gly:BA ratio & Conversion $^{\mathrm{a}}$ & \multicolumn{5}{c}{$\%$ selectivity } \\
\cline { 3 - 6 } & & $\mathrm{ME}$ & $\mathrm{DE}$ & $\mathrm{BE}$ & Other \\
\hline $1: 1$ & 20 & 8 & 1 & 90 & 1 \\
$3: 1$ & 23 & 60 & 2 & 37 & 1 \\
$5: 1$ & 8 & 89 & 4 & 5 & 2 \\
\hline
\end{tabular}

a $\%$ conversion of BA after 360 min reaction

The catalyst deactivation could be result of strong adsorption of glycerol on its surface.

On the other hand, the results presented in Table 3 show that the increase in the percentage of catalyst, based on the mass of glycerol, reflects a higher BA conversion $(5,23$ and $30 \%$ conversion for 5,10 and $15 \mathrm{wt} \%$ of catalyst, respectively). Nevertheless, the selectivity for the desired products decreases for the highest catalyst concentration.

Previous to this work, a lower dosage of catalyst was tested (2.5 wt \%), but we did not obtain significant benzyl alcohol conversion. Taking into account the results obtained in these exploratory tests, the experimental conditions selected to continue with catalytic studies are: temperature $393 \mathrm{~K}$, Gly:BA molar ratio 3:1 and a catalyst loading of 10 $\mathrm{wt} \%$.

\section{Comparison of the different carbonaceous systems}

Figure 4a depicts the conversion and selectivity values obtained for etherification of Gly with BA, using a 3:1 molar ratio and $10 \%$ of $\mathrm{Cc}-$ sulfonated catalysts. The results show that changes in the carbon functionalization method, $\mathrm{Cc}-\mathrm{SO}_{3} \mathrm{H}$ vs. $\mathrm{Cc}-\mathrm{PhSO}_{3} \mathrm{H}$, produce a considerable increase in the conversion ( 23 vs. $66 \%$, respectively) after $360 \mathrm{~min}$ of reaction. Although the difference in the acidity of both catalytic systems $\left(0.4\right.$ and $0.6 \mathrm{mmol} \mathrm{H}^{+} \mathrm{g}^{-1}$, respectively) is not quite significant, it is evident that the acid sites of the $\mathrm{Cc}-\mathrm{PhSO}_{3} \mathrm{H}$ catalyst are more efficient than those generated from the treatment with concentrated sulfuric acid $\left(\mathrm{Cc}-\mathrm{SO}_{3} \mathrm{H}\right)$. That is, the $\mathrm{H}^{+}$of $-\mathrm{PhSO}_{3} \mathrm{H}$ group are more available for the protonation of $\mathrm{BA}$, which will then lose a

Table 3 Etherification of Gly with BA, using a molar ratio 3:1, $393 \mathrm{~K}$ and different percentage of $\mathrm{Cc}-\mathrm{SO}_{3} \mathrm{H}$ catalyst

\begin{tabular}{lclccc}
\hline \% catalyst & Conversion $\%^{\mathrm{a}}$ & \multicolumn{4}{l}{$\%$ selectivity } \\
\cline { 3 - 6 } & & ME & DE & BE & Other \\
\hline 5 & 5 & 54 & 1 & 44 & 1 \\
10 & 23 & 60 & 2 & 37 & 1 \\
15 & 30 & 42 & 2 & 54 & 2 \\
\hline
\end{tabular}

a\% conversion of BA after 360 min reaction
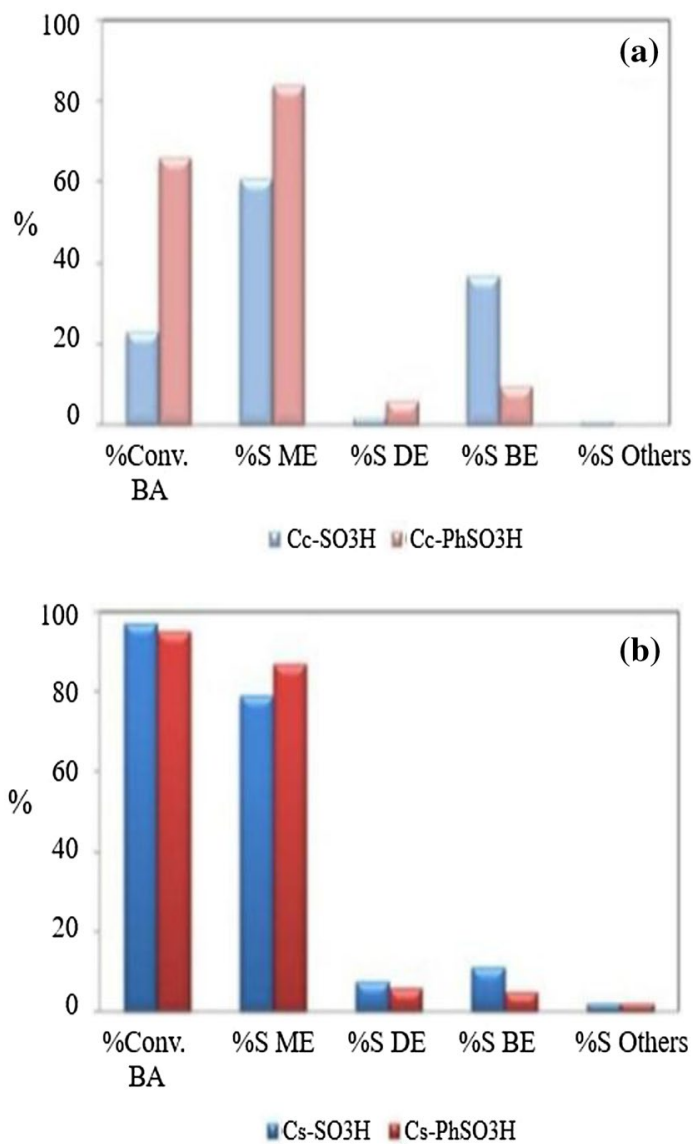

Fig. 4 Conversion of BA and selectivity obtained with different carbon catalysts: Cc-systems (a) and Cs-systems (b). Reaction conditions: Gly:BA molar ratio 3:1, $10 \mathrm{wt} \%$ of catalyst, $393 \mathrm{~K}$ and $360 \mathrm{~min}$ reaction time

water molecule to became a carbocation, which in turn will be attacked by either Gly or another BA molecule.

The distribution of products also shows differences between the catalysts. The selectivity for $\mathrm{ME}+\mathrm{DE}$ increased from 62 to $90 \%$ and the selectivity for $\mathrm{BE}$ diminished from 37 to $10 \%$ for $\mathrm{Cc}-\mathrm{SO}_{3} \mathrm{H}$ and $\mathrm{Cc}-\mathrm{PhSO}_{3} \mathrm{H}$, respectively.

The formation of $\mathrm{ME}$ and $\mathrm{DE}$ agrees with the results published in the literature, where it has been reported that etherification of glycerol is preferentially in the primary hydroxyl groups of glycerol. ME formation is favored during the etherification, due to the reaction equilibrium reached in the presence of the water produced. The presence of water decreases the amounts of DE and TE formed, through their own hydrolysis (Gonçalves et al. 2014; Cannilla 2014). Therefore, the high monoether selectivity observed, along with the appreciable amount of BE found in the present study, could be explained taking into account that the water produced was not removed from the reaction medium.

The catalytic performance of Cc-functionalized carbon was compared to carbon synthetized in our laboratory 
(Cs) in the glycerol etherification with BA. The results for the $\mathrm{Cs}-\mathrm{SO}_{3} \mathrm{H}$ and $\mathrm{Cs}-\mathrm{PhSO}_{3} \mathrm{H}$ catalysts are presented in Fig. 4b. As can be seen, an almost complete conversion of BA (97 and $95 \%$ for $\mathrm{Cs}-\mathrm{SO}_{3} \mathrm{H}$ and $\mathrm{Cs}-\mathrm{PhSO}_{3} \mathrm{H}$, respectively) is achieved after $360 \mathrm{~min}$ of reaction. The remarkable improvement in the catalytic performance can be attributed to successful incorporation of sulfonic groups, as well as other oxygenated surface groups, in particular carboxylic acids, which cause an increase of hydrophilicity of the solid surface, favoring the adsorption of Gly and BA. Zhao et al. (2010b) suggest that sulphonic acid groups are responsible for the improvement in the conversion of glycerol to its ethers. The presence of these groups does not limit the accessibility of reagents and products inside and outside the active sites; thus, high catalytic performance is reached despite the small surface area of the systems.

Both $\mathrm{Cs}-\mathrm{SO}_{3} \mathrm{H}$ and $\mathrm{Cs}-\mathrm{PhSO}_{3} \mathrm{H}$ catalysts were selective towards $\mathrm{ME}+\mathrm{DE}$, giving $87 \%$ and $93 \%$ selectivity, respectively (at the final time of reaction). For the $\mathrm{Cs}-\mathrm{SO}_{3} \mathrm{H}$ system, $11 \%$ selectivity was also observed for the self-condensation product (BE), whereas for $\mathrm{Cs}-\mathrm{PhSO}_{3} \mathrm{H}$ catalyst, $\mathrm{BE}$ only reached 5\% selectivity. Thus, it can be concluded that the $-\mathrm{PhSO}_{3} \mathrm{H}$ group functionalized system resulted in the most active and selective of the prepared catalysts.

Further, the results obtained in this work using Cs- $\mathrm{SO}_{3} \mathrm{H}$ and $\mathrm{Cs}-\mathrm{PhSO}_{3} \mathrm{H}$ are similar and/or better than those reported in the literature. $\mathrm{Gu}$ et al. (2008) obtained with the $\mathrm{C}-\mathrm{SO}_{3} \mathrm{H}$ system only $12 \%$ yield. Gonzalez-Arellano et al. (2015) concluded that Zeolite ZSM-5 could be used as a good catalyst to produce ME (60\%) and DE (38\%), with little BE formation (2\%), for $80 \%$ of BA conversion after $8 \mathrm{~h}$ reaction. Da Silva et al. (2009) obtained $100 \%$ of conversion after 120 min of reaction with the systems Amberlyst-35 and Zeolite $\beta$, but the product distribution was not entirely satisfactory.

\section{Reusability of the catalysts}

The reuse reactions were carried out at $393 \mathrm{~K}$ using the 3:1 Gly:BA molar ratio and the functionalized carbons $\mathrm{Cs}-\mathrm{SO}_{3} \mathrm{H}$ and $\mathrm{Cs}-\mathrm{PhSO}_{3} \mathrm{H}$. It is important to note that no reactivation treatment was performed on the catalyst after each reaction cycle. The catalyst was subject only to a few washing and drying stages.

For both systems, Cs- $\mathrm{SO}_{3} \mathrm{H}$ and $\mathrm{Cs}-\mathrm{PhSO}_{3} \mathrm{H}$, a similar behavior is observed (Fig. 5) after each reuse. The final conversion decreased between 20 and $30 \%$ for each reaction cycle. According to the results of our studies, the vulnerability of active sites can be assigned to different deactivation factors, such as leaching or blocking of acidic sites because the adsorbed substrates cannot be removed by washing the catalyst. These results are in agreement with other publications (Gonçalves et al. 2016; Fraile et al. 2012). These

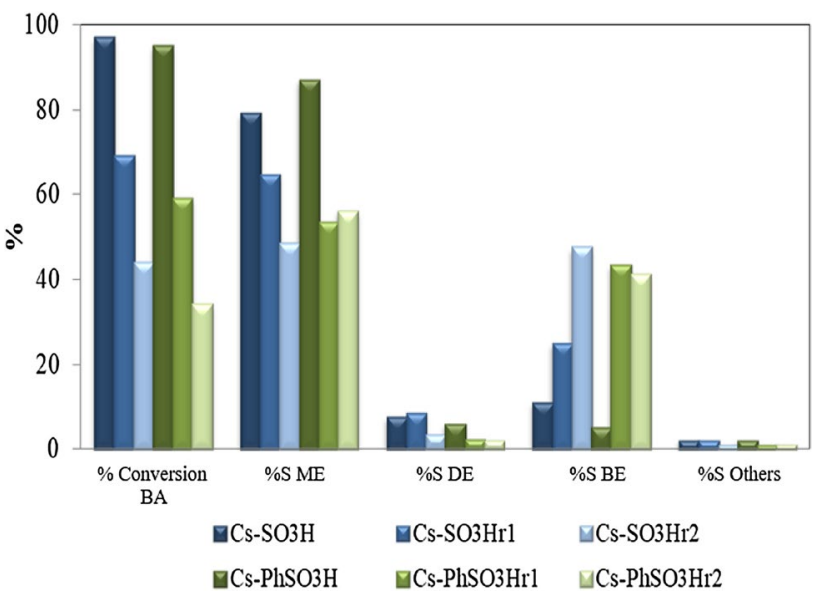

Fig. 5 Cs-functionalized systems reuse in the Gly etherification with BA. Reaction conditions: Gly:BA molar ratio 3:1, $10 \mathrm{wt} \%$ of catalyst, $393 \mathrm{~K}$ and $360 \mathrm{~min}$

catalysts were employed in different experiments published in the literature and the results confirm that leaching is one of motive of loss catalytic activity (Suwannakarn et al. 2008). Nevertheless the selectivity to ME + DE was kept between the second and third cycle for the best catalyst $\left(\mathrm{Cs}-\mathrm{PhSO}_{3} \mathrm{H}\right)$.

\section{Conclusions}

The catalytic behavior of $\mathrm{Cc}-\mathrm{SO}_{3} \mathrm{H}$ was studied in the etherification of Gly with BA. The results obtained allowed us to optimize the reaction parameters. A molar ratio Gly:BA of $3: 1$ and a catalyst percentage of $10 \%$ were chosen. Changing the carbon functionalization method $\left(-\mathrm{PhSO}_{3} \mathrm{H}\right.$ for $-\mathrm{SO}_{3} \mathrm{H}$ groups) produced a considerable increase in glycerol conversion (from 23 to 66\%) and in selectivity for $\mathrm{ME}+\mathrm{DE}$ (from 62 to $90 \%$ ). The $\mathrm{Cs}-\mathrm{SO}_{3} \mathrm{H}$ and $\mathrm{Cs}-\mathrm{PhSO}_{3} \mathrm{H}$ catalysts were obtained from synthesized carbon. These catalytic systems were highly active (97 and 95\%, respectively) and selective. The main reaction product was ME (79 and $87 \%$, respectively). The possibility of $\mathrm{Cs}-\mathrm{SO}_{3} \mathrm{H}$ and $\mathrm{Cs}-\mathrm{PhSO}_{3} \mathrm{H}$ catalyst reuse was investigated in three successive reactions. It was observed that the final conversion decreased between 20 and $30 \%$ for each cycle, but the selectivity for ME $+\mathrm{DE}$ was kept between the second and third cycle for $\mathrm{Cs}-\mathrm{PhSO}_{3} \mathrm{H}$. Therefore, this work shows an alternative route (functionalization with $-\mathrm{PhSO}_{3} \mathrm{H}$ ) to transform carbonaceous systems into acid catalysts with promising application in glycerol etherification.

Acknowledgement This work was supported by the Universidad Nacional de La Plata (Projects X633 and X700), CONICET (PIP N ${ }^{\circ}$ 
0276) and ANPCyT (PICT 2014-0679) from Argentina. The authors are grateful to Pablo Fetsis, CINDECA technician, for BET analysis.

\section{References}

Alonso DM, Wettsteina SG, Dumesic JA (2012) Bimetallic catalysts for upgrading of biomass to fuels and chemicals. Chem Soc Rev 41:8075-8098

Anitha M, Kamarudin SK, Kofli NT (2016) The potential of glycerol as a value-added commodity. Chem Eng J 295:119-130

Boehm HP (1994) Some aspects of the surface chemistry of carbon blacks and other carbons. Carbon 32(5):759-769

Bohon MD, Metzger BA, Linak WP, King CJ, Roberts WL (2011) Glycerol combustion and emissions. Proc Combust Inst $33: 2717-2724$

Bozkurt OD (2015) Alternative fuel additives from glycerol by etherification with isobutene: structure-performance relationships in solid catalysts. Fuel Process Technol 138:780-804

Cannilla C (2014) Glycerol etherification with TBA: high yield to poly-ethers using a membrane assisted batch reactor. Environ Sci Technol 48:6019-6026

Da Silva CRB, Gonçalves VLC, Lachter ER, Mota CJA (2009) Etherification of glycerol with benzyl alcohol catalyzed by solid acids. J Braz Chem Soc 20(2):201-204

Faroppa ML, Musci JJ, Chiosso ME, Caggiano CG, Bideberripe HP, García Fierro JL, Siri GJ, Casella ML (2016) Oxidation of glycerol with $\mathrm{H}_{2} \mathrm{O}_{2}$ on $\mathrm{Pb}$-promoted $\mathrm{Pd} / \gamma-\mathrm{Al}_{2} \mathrm{O}_{3}$ catalysts. Chin J Catal 37:1982-1990

Figueiredo JL, Pereira MFR (2010) The role of surface chemistry in catalysis with carbons. Catal Today 150:2-7

Figueiredo JL, Pereira MFR, Freitas MMA, Órfão JJM (1999) Modification of the surface chemistry of activated carbons. Carbon 37:1379-1389

Fraile JM, García-Bordejé E, Roldán L (2012) Deactivation of sulfonated hydrothermal carbons in the presence of alcohols: evidences for sulfonic esters formation. J Catal 289:73-79

Gonçalves M, Souza VC, Galhardo TS, Mantovani M, Figueiredo FCA, Mandelli D, Carvalho WA (2013) Glycerol conversion catalyzed by carbons prepared from agroindustrial wastes. Ind Eng Chem Res 52:2832-2839

Gonçalves M, Mantovani M, Alves Carvalho W, Rodrigues R, Mandelli D, Silvestre Albero J (2014) Biodiesel wastes: an abundant and promising source for the preparation of acidic catalysts for utilization in etherification reaction. Chem Eng J 256:468-474

Goncalves M, Castro CS, Oliveira LCA, Carvalho WA (2015) Green acid catalyst obtained from industrial wastes for glycerol etherification. Fuel Process Technol 138:695-703

Gonçalves M, Coelho Solera F, Isoda N, Alves Carvalho W, Mandellia D, Sepúlveda J (2016) Glycerol conversion into value-added products in presence of a green recyclable catalyst: acid black carbon obtained from coffee ground wastes. J Taiwan Inst Chem Eng 60:294-301

González-García P (2018) Activated carbon from lignocellulosics precursors: a review of the synthesis methods, characterization techniques and applications. Renew Sustain Energy Rev 82:1393-1414

Gonzalez-Arellano C, Grau-Atienzab A, Serrano E, Romero AA, Garcia-Martinez J, Luque R (2015) The role of mesoporosity and $\mathrm{Si} / \mathrm{Al}$ ratio in the catalytic etherification of glycerol with benzyl alcohol using ZSM-5 zeolites. J Mol Catal A: Chem 406:40-45

Gu Y, Azzouzi A, Pouilloux Y, Jérôme F, Barrault J (2008) Heterogeneously catalyzed etherification of glycerol: new pathways for transformation of glycerol to more valuable chemicals. Greem Chem 10:164-167
Han S, Kim M, Hyeron T (2003) Direct fabrication of mesoporous carbons using in situ polymerized silica gel networks as a template. Carbon 41:1525-1532

Janaun J, Ellis N (2010) Glycerol eherification by tert-butanol catalyzed by sulfonated carbon catalyst. J Appl Sci 10(21):2633-2637

Jaworski MA, Vega S, Siri GJ, Casella ML, Romero Salvador A, Santos López A (2015) Glycerol etherification with benzyl alcohol over sulfated zirconia catalysts. Appl Catal: Gen 505:36-43

Len C, Luque R (2014) Continuous flow transformations of glycerol to valuable products: an overview. Sustain Chem Process 2:1

Liu R, Xiqing W, Zhao X, Fen P (2008) Sulfonated ordered mesoporous carbon for catalytic preparation of biodiesel. Carbon 46:1664-1669

Liu X-Y, Huang M, Ma H-L, Zhang Z-Q, Gao J-M, Zhu Y-L, Han X-J, Guo X-Y (2010) Preparation of a carbon-based solid acid catalyst by sulfonating activated carbon in a chemical reduction process. Molecules 15:7188-7196

Liu T, Li Z, Li W, Shi C, Wanga Y (2013) Preparation and characterization of biomass carbon-based solid acid catalyst for the esterification of oleic acid with methanol. Bioresour Technol 133:618-621

Martínez Fierro MC (2012) Preparación y caracterización de carbón activo a partir de lignina para su aplicación en procesos de descontaminación de aguas. Universidad Autónoma de Madrid, Madrid

Mo X, López DE, Suwannakarn K, Liu Y, Lotero E, Goodwin JG Jr, Lu C (2008) Activation and deactivation characteristics of sulfonated carbon catalysts. J Catal 254:332-338

Nersasian A, Johson PR (1965) Infrared spectra of alkanesulfonic acids, chlorosulfonated polyethylene and their derivatives. J Appl Polym Sci 9:1653-1668

Pagliaro M, Ciriminna R, Kimura H, Rossi M, Della Pina C (2007) From glycerol to value-added products. Angew Chem Int Ed 46:4434-4440

Rodríguez-Reinoso F (1998) The role of carbon materials in heterogeneous catalysis. Carbon 36:159-175

Sánchez JA, Hernández DL, Moreno JA, Mondragón F, Fernández JJ (2011) Alternative carbon based acid catalyst for selective esterification of glycerol to acetylglycerols. Appl Catal A 405:55-60

Suwannakarn K, Lotero E, Goodwin JG Jr, Lu Ch (2008) Stability of sulfated zirconia and the nature of the catalytically active species in the transesterification of triglycerides. J Catal 255:279-286

Tao M-L, Guan H-Y, Wang X-H, Liu Y-Ch, Louh R-F (2015) Fabrication of sulfonated carbon catalyst from biomass waste and its use for glycerol esterification. Fuel Process Technol 138:355-360

Toda M, Takagaki A, Okamura M, Kondo JN, Hayashi S, Domen K, Hara M (2005) Biodiesel made with sugar catalyst. Nature 438:178-179

Toufiq Reza M, Nover J, Wirth B, Coronella CJ (2016) Hydrothermal carbonization of glucose in saline solution: sequestration of nutrients on carbonaceous materials. AIMS Energy 4(1):173-189

Zhao W, Yang B, Yi C, Lei Z, Xu J (2010a) Etherification of glycerol with isobutylene to produce oxygenate additive using sulfonated peanut shell catalyst. Ind Eng Chem Res 49:12399-12404

Zhao Y, Wang H, Zhao Y, Shen J (2010b) Preparation of a novel sulfonated carbon catalyst for the etherification of isopentene with methanol to produce tertamyl methyl ether. Catal Commun 11:824-828

Zong M, Duan Z, Lou W, Smith TJ, Wua H (2007) Preparation of a sugar catalyst and its use for highly efficient production of biodiesel. Green Chem 9:434-437

Publisher's Note Springer Nature remains neutral with regard to jurisdictional claims in published maps and institutional affiliations. 